DR. CLANNY AND HIS REVIEWERS.

\section{To the Editor of The Larcet.}

$S_{1 n,-F o r ~ t h r e e ~ m o n t h s ~} I$ have been at different times engaged in ascertaining. by new processes, the relative proportions of free carbon in the blood of persons in whom the sanguineous system was affected, and the contrary. My memoranda are in train for publication, and as I have heretofore preserited to you for insertion several papers upon the chemical pathology of the fluids of the human body, I shall continue so to do, though the uncalledfor severity, I had almost written asperity, with which my work on cholera was criticised, by interested individuals, in two London hebdomadal publications, almost deter me from making anything public upon this subject, except under the form of a separate publication. My desire has been to steer clear of personalities and of controversies; at the same time I beg to remark, that $I$ value not personal invective or critical vituperation, knowing that those who deal most largely in this way are the least likely to give satisfaction to their readers, or to afford assurance that, in turn, they may escape that which all honourable men detest, viz., ill-natured animadversions. In conclusion I assert, without fear of contradiction, that what I have heretofore written on chemical pathology is just and correct. I remain, Mr. Editor, your most obedient, very humble servant, W. Reid $C_{\text {Ianny. }}$ Sunderland, Sept. 15, 1832.

IATE TNQUFST AT RORTSEA.

\section{To the Editor of ThE LANCET.}

SIR, - I have read the letter inserted in The Lances of the first instant, under the title " Non-Medical Coroners;" and I think it right to observe, that your correspondent has mis-stated the proceedings at the inquest, as to what was said by the coroner to the jury, and also as to the verdict.

The coroner did not state to the jury " that be had no power to order an in. spection," nor did he ever entertain such an opinion.

The evidence of the two witnesses who saw the accident, was so clear as to the cause of the death of the deceased, that it was entirely unnecessary to open the body, and as the parents of the child (who are Jews) were exceedingly averse to it, such examination would haye been doing violence

\section{ST. THOMAS'S HOSPITAL.}

SUCCESSFU ADAINISTRATION OF

PURE NICOTINE,

DISSOLVED IN DILUTE SULPHURIC ACID,

$$
\text { IN AGUE. }
$$

SIR,-I take the liberty of sending you the three accompanying cases, trusting that you will give them publicity through the medium of your widely extended journal, and with the hope that some of my professional brethren may be induced to try the remedy, and report through the same medium how far their experience corroborates my own. I have the honour to be, Sir,

Your humble servant, H. S. Roots.

84, Guilford-street, Russell-square,

September 18, 1832.

It is now between six and seren years since I was engaged in St. Pancras Iufirmary, in conjunction with my colleague Mr. Wright, in a series of experiments on the different principles resident in opium, more especially morphia, narcotine, and meconic acid ; and having (at least to my own satisfaction) convinced myself that morphia was the only substance which contained the soporific, narcotic, stimulating and constipating powers of that drug; and having found that, in opposition to what has been stated by Dr. Magendie, pure narcotiue might be given even in scruple doses to an adult, whether dissolved in oil, sulphuric ether, or acetic acid, without the slightest deleterious result; and having in several instances administered five grains of pure narcotine dissolved in oil, and the same quantity in acetic acid, to two different dogs without any manifest effect,-it was my intention to have offered these experiments to the public. Circumstances, however, prevented my so doing, and it was in the spring of the present year only that $\mathrm{mJ}$ attention was recalled to the subject, by finding that pure narcotine dissolved in di lute sulphuric acid, posnesses a bitternes 